\title{
New insights into the evolution of subtilisin-like serine protease genes in Pezizomycotina
}

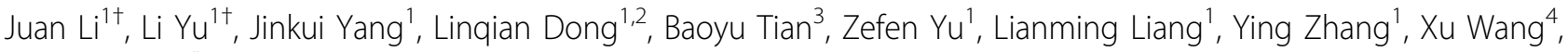 \\ Keqin Zhang ${ }^{1 *}$
}

\begin{abstract}
Background: Subtilisin-like serine proteases play an important role in pathogenic fungi during the penetration and colonization of their hosts. In this study, we perform an evolutionary analysis of the subtilisin-like serine protease genes of subphylum Pezizomycotina to find if there are similar pathogenic mechanisms among the pathogenic fungi with different life styles, which utilize subtilisin-like serine proteases as virulence factors. Within Pezizomycotina, nematode-trapping fungi are unique because they capture soil nematodes using specialized trapping devices. Increasing evidence suggests subtilisin-like serine proteases from nematode-trapping fungi are involved in the penetration and digestion of nematode cuticles. Here we also conduct positive selection analysis on the subtilisin-like serine protease genes from nematode-trapping fungi.

Results: Phylogenetic analysis of 189 subtilisin-like serine protease genes from Pezizomycotina suggests five strongly-supported monophyletic clades. The subtilisin-like serine protease genes previously identified or presumed as endocellular proteases were clustered into one clade and diverged the earliest in the phylogeny. In addition, the cuticle-degrading protease genes from entomopathogenic and nematode-parasitic fungi were clustered together, indicating that they might have overlapping pathogenic mechanisms against insects and nematodes. Our experimental bioassays supported this conclusion. Interestingly, although they both function as cuticle-degrading proteases, the subtilisin-like serine protease genes from nematode-trapping fungi and nematode-parasitic fungi were not grouped together in the phylogenetic tree. Our evolutionary analysis revealed evidence for positive selection on the subtilisin-like serine protease genes of the nematode-trapping fungi.

Conclusions: Our study provides new insights into the evolution of subtilisin-like serine protease genes in Pezizomycotina. Pezizomycotina subtilisins most likely evolved from endocellular to extracellular proteases. The entomopathogenic and nematode-parasitic fungi likely share similar properties in parasitism. In addition, our data provided better understanding about the duplications and subsequent functional divergence of subtilisin-like serine protease genes in Pezizomycotina. The evidence of positive selection detected in the subtilisin-like serine protease genes of nematode-trapping fungi in the present study suggests that the subtilisin-like serine proteases may have played important roles during the evolution of pathogenicity of nematode-trapping fungi against nematodes.
\end{abstract}

\section{Background}

Subtilisin-like serine proteases play an important role in the pathogenicity of pathogenic fungi. By using subtilisin-like serine proteases, pathogenic fungi disrupt the physiological integrity of the hosts during penetration and colonization [1,2]. Previous studies have suggested

\footnotetext{
* Correspondence: kqzhang111@yahoo.com.cn

+ Contributed equally

'Laboratory for Conservation and Utilization of Bio-resources, and Key Laboratory for Microbial Resources of the Ministry of Education, Yunnan University, Kunming, 650091, PR China
}

that pathogenic fungi with different life styles utilize subtilisin-like serine proteases as their virulence factor [2-5]. Investigations into the similarities and differences of pathogenic mechanisms among these pathogenic fungi will significantly enhance our understanding of the evolution of these genes.

Pezizomycotina, the largest subphylum of Ascomycota, includes all filamentous, sporocarp-producing species. These organisms have diverse ecological niches and life styles [6]. A recent study based on six nuclear genes divided Pezizomycotina into nine major clades [7].
C Biomed Central

(ㄷ) $2010 \mathrm{Li}$ et al; licensee BioMed Central Ltd. This is an Open Access article distributed under the terms of the Creative Commons Attribution License (http://creativecommons.org/licenses/by/2.0), which permits unrestricted use, distribution, and reproduction in any medium, provided the original work is properly cited. 
Among them, nematode-trapping fungi, which are conidial anamorphs of Orbiliomycetes and belong to nematophagous fungi, are unique because they capture free-livingsoil nematodes using trapping devices (e.g. adhesive networks, constricting rings, adhesive columns, adhesive knobs and nonconstricting rings) [8,9]. In contrast, nematode-parasitic fungi, another group of nematophagous fungi within Pezizomycotina, infect nematodes mainly using extracellular enzymes (subtilisin-like serine protease, chitinase and etc.) $[2,10]$. Previous studies have suggested that subtilisin-like serine proteases are involved in the penetration and the digestion of nematode cuticles [11-23]. However, only limited studies have been done on the evolutionary pattern of subtilisin-like serine protease genes in nematode-trapping fungi so far $[10,11,17]$. In view of this, we here newly determined five subtilisin-like serine protease genes from the nematode-trapping fungi. In conjunction with the other Pezizomycotina sequences obtained from previous studies and extensive database searching of available genome assembly, we perform the most comprehensive investigation to date of subtilisin-like serine protease genes in Pezizomycotina.

\section{Results}

New subtilisin-like serine protease genes from nematodetrapping fungi

Table 1 summarizes the sequence characterizations of newly determined subtilisin-like serine protease genes from five nematode-trapping fungi. The five sequences range from 1176-bp to 1288-bp in length and all contain an intron. The encoding genes of these five subtilisinlike serine proteases have been submitted to GenBank (Accession nos. EF113088 - EF113092).

Generally, the subtilisin-like serine proteases from nematode-trapping fungi, together with those from nematode-parasitic fungi and entomopathogenic fungi, were classified as cuticle-degrading proteases because they were involved in the penetration and digestion of nematode or insect cuticles [11-23]. Our analyses indicated that the subtilisin-like serine protease genes from nematode-trapping fungi shared a high degree of sequence similarity to those from nematode-parasitic fungi and entomopathogenic fungi. As seen from Figure 1 , these subtilisin-like serine protease genes share a prepro-peptide structure. The signal peptides consisted of 15-21 amino acids. The potential catalytic triad residues (His, Asp and Ser) and the substrate-binding $S_{1}$ pocket (Ser-Leu-Gly-Gly and Ala-Ala-Gly) were all conserved among these sequences. Moreover, two cysteines which contribute to the stability of the tertiary structure of proteases [24] were also conserved.

\section{Phylogenetic analyses}

Using various tree-building methods, our phylogenetic analyses based on a total of 189 subtilisin-like serine protease genes using various tree-building methods consistently showed five strongly-supported monophyletic clades. These clades are designated as A-E in the trees (Figure 2; Additional files 1, 2 and 3).

Our phylogenetic tree (Figure 2) clustered the cuticledegrading protease genes from entomopathogenic and nematode-parasitic fungi into clade A with the exclusion of nematode-trapping fungi $(\mathrm{BS}=81)$. The genes from nematode-trapping fungi all grouped into clade $\mathrm{D}$ ( $\mathrm{BS}=$ 99). Clade B contained the subtilisin-like serine protease genes from fungi causing dermatosis in humans and animals. Clade E comprised sequences from four classes of Pezizomycotina (Sordariomycetes, Eurotiomycetes, Leotiomycetes and Dothideomycetes), as well as vacuolar protease genes [5,25-28], indicating the possible endocellular origin of these proteases.

Although the inconsistent relationships among the five clades were produced in our phylogenetic analyses, the earliest divergence of Clade E was strongly supported in all tree topologies (Figure 2; Additional files 1, 2 and 3). The alternative tree topologies, in which Clade E was not the basal clade in the phylogeny, were all found to be significantly worse than our tree $(P<0.05)$.

\section{Signatures of positive selection in the nematode-trapping fungi}

One of the intriguing findings in our study is evidence of positive selection in the nematode-trapping fungi. Maximum parsimony (MP), neighbor-joining (NJ), maximum-likelihood (ML) and Bayesian tree reconstructions

Table 1 Basic information of cloned cuticle-degrading proteases from nematode-trapping fungi.

\begin{tabular}{|c|c|c|c|c|c|c|c|c|}
\hline Gene & Accession no. & Species name & Whole/partial & Length (bp) & Intron (number) & Intron length (bp) & $\mathrm{aa}^{\mathrm{a}}$ & Molecular mass $^{b}$ \\
\hline$A m 1$ & EF113088 & A. musiformis & whole & 1288 & 1 & 58 & 409 & $42 \mathrm{kDa}$ \\
\hline Ay1 & EF113089 & A. yunnanensis & whole & 1283 & 1 & 52 & 409 & 42 kDa \\
\hline $\mathrm{MCl}$ & EF113090 & M. coelobrochum & whole & 1284 & 1 & 53 & 409 & $42 \mathrm{kDa}$ \\
\hline Mp1 & EF113091 & M. psychrophilum & partial & 1176 & 1 & 54 & 373 & \\
\hline Ds1 & EF113092 & D. shizishanna & whole & 1273 & 1 & 58 & 404 & $41.3 \mathrm{kDa}$ \\
\hline
\end{tabular}

a Number of amino acids in primary translation product

b, Molecular mass was calculated online with ProtParam tools http://us.expasy.org/tools/protparam.html. 

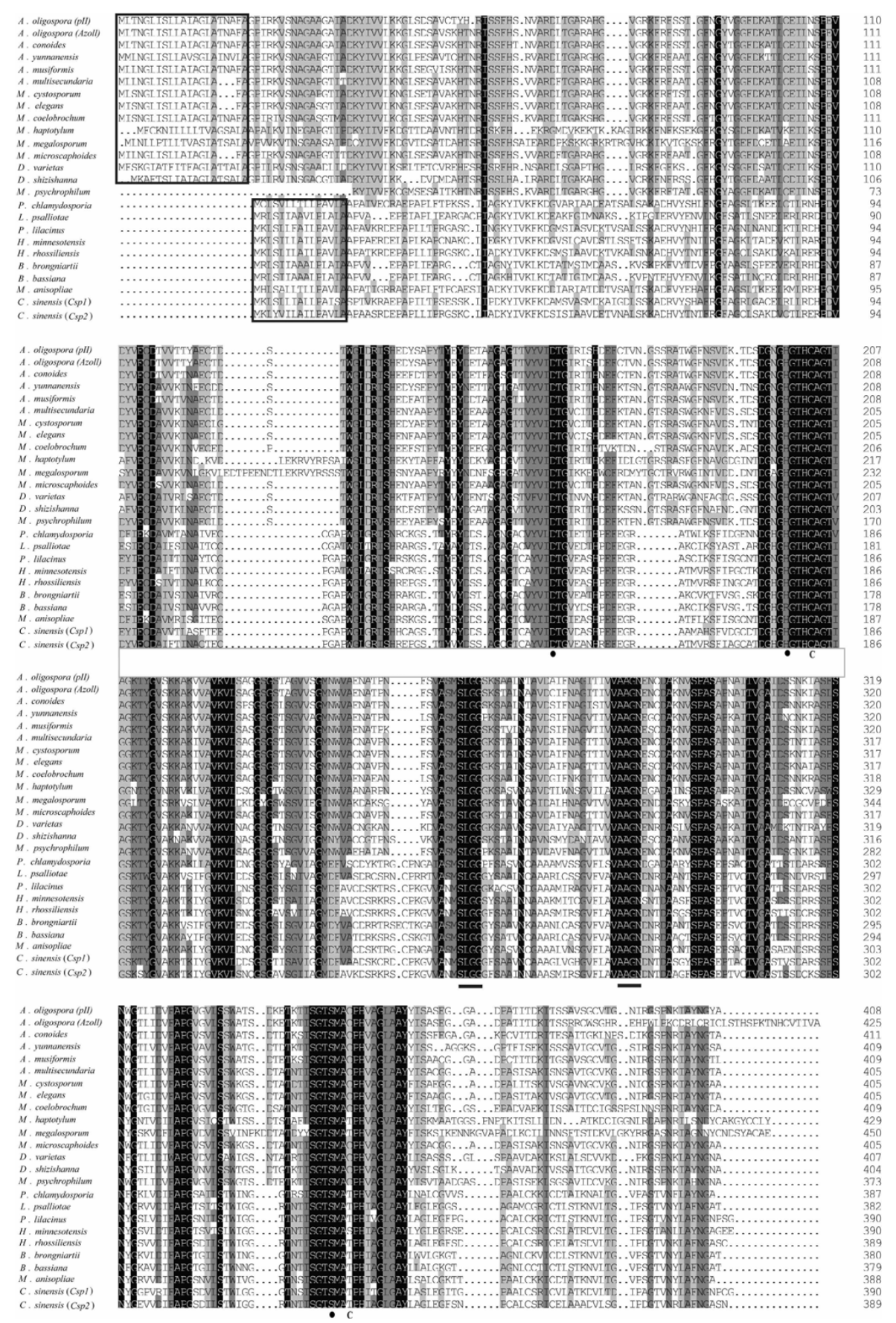

Figure 1 Alignment of the cuticle-degrading protease sequences from nematophagous and entomopathogenic fungi. Areas shaded in black are conserved regions (100\% similarity), areas shaded in grey have a high degree of homology (more than $75 \%$ similarity) and unshaded areas are regions of variability between the proteases. Signal peptide sequences were encompassed by frame with black edge. • indicates the aspartic acid $\left(\mathrm{Asp}_{41}\right.$ )-histidine ( $\left.\mathrm{His}_{77}\right)$-serine $\left(\mathrm{Ser}_{231}\right.$ ) (in EF113092) catalytic triad. C indicates the conserved cysteines. The underlined regions are the substrate-binding $S_{1}$ pocket in subtilisin-like serine protease gene. GenBank number: Arthrobotrys oligospora (PI), X94121; Arthrobotrys oligospora (Azol1), AF516146; Arthrobotrys conoides, AY859782; Arthrobotrys yunnanensis, EF113089; Arthrobotrys musiformis, EF113088; Arthrobotrys multisecundaria, EF055263; Monacrosporium cystosporum, AY859780; Monacrosporium elegans, AY859781; Monacrosporium coelobrochum, EF113091; Monacrosporium haptotylum EF681769; Monacrosporium megalosporum, AB120125; Monacrosporium microscaphoides, AY841167; Dactylella varietas, DQ531603; Dactylella shizishanna, EF113092; Monacrosporium psychrophilum, EF113090;Pochonia chlamydosporia, AJ427460; Lecanicillium psalliotae, AY692148; Paecilomyces lilacinus, EF094858; Hirsutella minnesotensis, EF560594; Hirsutella rhossiliensis, DQ422145; Beauveria brongniartii, AY520814; Beauveria bassiana, EF195164;Metarhizium anisopliae, M73795; Cordyceps sinensis (Csp1), EU282382; Cordyceps sinensis (Csp2), EU282383. 


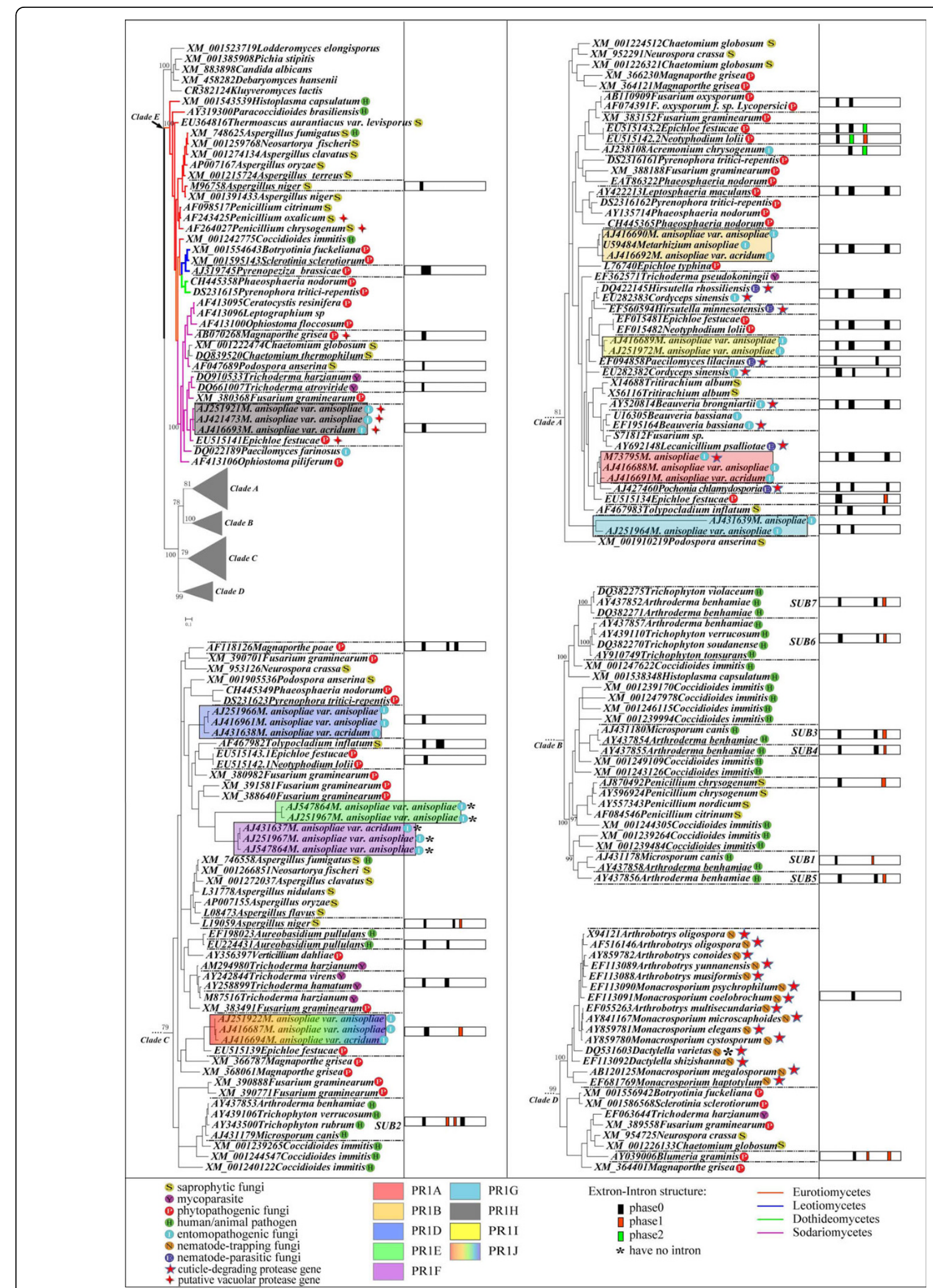

Figure 2 Phylogenetic tree based on amino acid sequences of subtilisin-like serine protease genes. The tree was constructed using MrBayes 3.1.2 [49]. The right frame diagrams show the intron distribution (position and phase) in corresponding proteins. SUB1-7 means seven genes encoding putative subtilisin-like serine proteases isolated from dermatophytic fungi. 


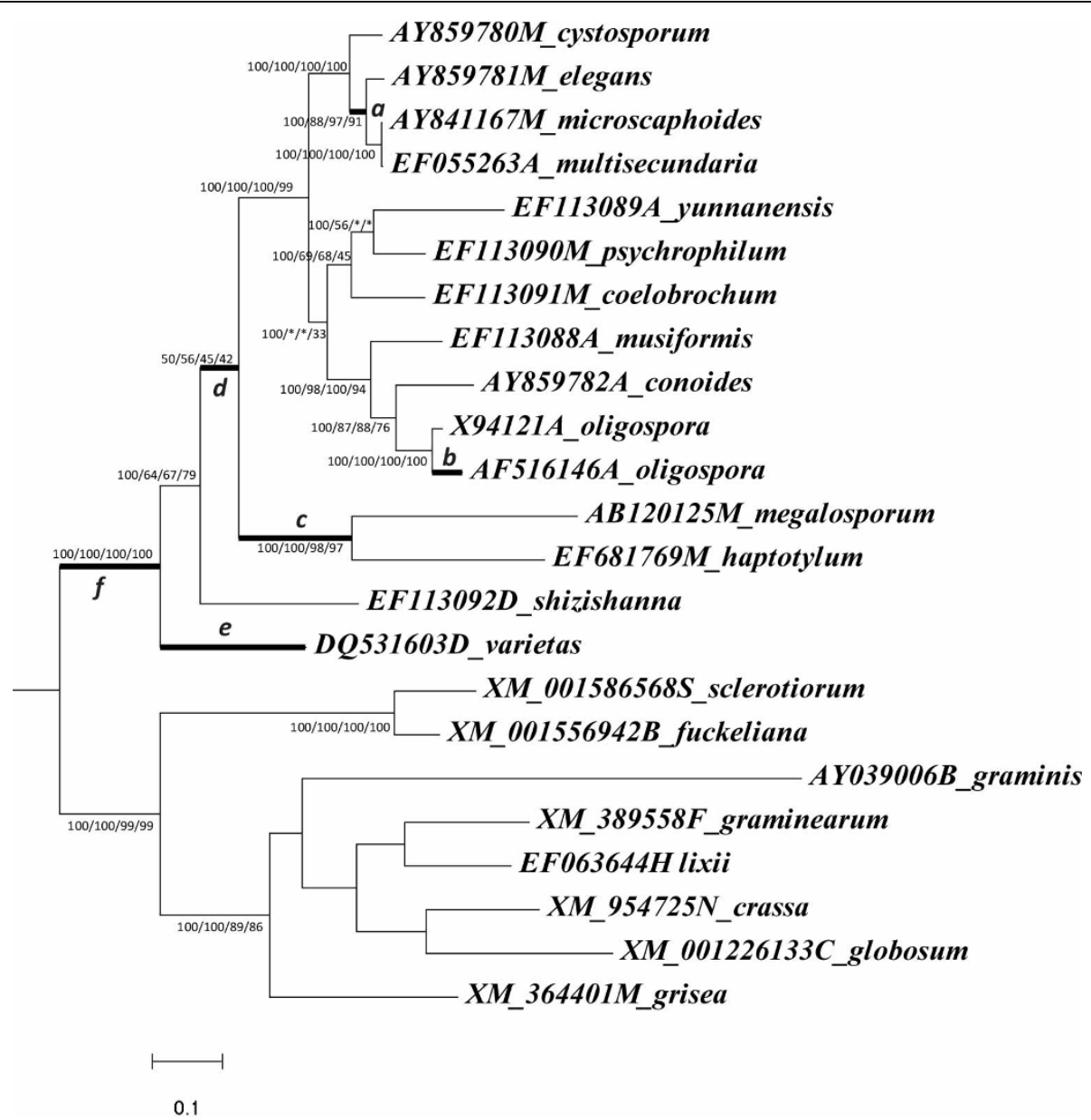

Figure 3 Phylogeny based on subtilisin-like serine protease genes from nematode-trapping fungi used for ML analysis in PAML and Bn-Bs. Maximum parsimony (MP), neighbor-joining (NJ), maximum-likelihood (ML) and Bayesian tree reconstructions of the subtilisin-like serine protease gene sequences of clade D presented similar overall topologies. The bootstrap values of each branch for different methodologies are indicated (Bayesian/ML/NJ/MP). The symbol $\left(^{*}\right)$ indicates distinct topological arrangements. The thick branches indicate the branch with a significant LRT in the PAML branch analysis. After calculation using Bn-Bs, only branch $f(Z=3.66320)$ was significant.

of the subtilisin-like serine protease genes of nematodetrapping fungi presented similar overall topologies (Figure 3). Six branches (designated as $a-f$ ) showed signs of significant positive selection in all four tree topologies (Figure 3; Additional file 4). After Bonferroni correction for multiple testing, we found that likelihood ratio tests (LRT) were still significant in three branches (branch $b$, $e$ and $f$ ) in all tree topologies (Figure 3; Additional file 4). Several positively selected residues were also identified for these branches with high posterior probabilities (see Additional file 4). Bonferroni correction in PAML analyses may be insufficient because this correction lacks statistical power [29]. We also measured the patterns of selection pressures among nematode-trapping fungal genes using the Bn-Bs program, a relatively conservative method. The analysis using the Bn-Bs program also revealed that $d \mathrm{~N}$ was significantly greater than $d \mathrm{~S}$ for branch $f$, the ancestor branch of nematode-trapping fungi ( $Z=3.66320$; Figure 3$)$.

In sum, the results showed for the first time that positive selection might have acted on the subtilisin-like serine protease genes in nematode-trapping fungi, at least in the early stage of their evolution.

\section{Functional Bioassays}

The infection of insects and nematodes with entomopathogenic fungi and nematode-parasitic fungi One of the interesting results inferred from our phylogenetic analysis was the clustering of the cuticle-degrading protease genes from entomopathogenic and nematodeparasitic fungi. This result suggested that entomopathogenic fungi might have nematode-parasitic activities, and nematode-parasitic fungi might have entomopathogenic activities. To test this hypothesis, functional assays 
were conducted to determine whether the nematodeparasitic fungi could infect insects, and whether the entomopathogenic fungi could infect nematodes. Specifically, the entomopathogenic and nematode-parasitic fungi (Table 2) were tested on their potential to infect the eggs of both the root-knot nematode Meloidogyne sp. and the potato tuber moth Phthorimaea opercullella. The phytopathogenic fungus Nigrospora oryzae was used as the negative control.

Our bioassay result on the eggs of the root-knot nematode Meloidogyne sp. indicated that all eight entomopathogenic or nematode-parasitic fungi could infect the eggs of the root-knot nematode (Figure 4). As seen from the histogram of Figure 4-II, the infection rate of these eight fungi ranged from $73 \%$ to $100 \%$ after 1 week, while the phytopathogenic fungus $N$. oryzae couldn't infect any egg.

The bioassay on the eggs of $P$. opercullella indicated that all eight entomopathogenic or nematode-parasitic fungi could infect the eggs of the potato tuber moth (Figure 5). After 3 days of co-incubation, the juveniles hatched from the eggs. Five days later, the infection rates of the eight entomopathogenic or nematode-parasitic fungi were obtained and they ranged from $80 \%$ to $100 \%$ (Figure 5-II). For the negative control, all the potato tuber moth eggs hatched into juveniles within 5 days (Figure 5-I-I).

In sum, our bioassay results indicated that entomopathogenic and nematode-parasitic fungi could infect both nematode and insect eggs, thus supporting the inference from the phylogenetic analyses.

\section{Effects of the subtilisin-like serine protease PSP-3 on the} nematode and insect eggs

Subtilisin-like serine proteases are known to play a key role during penetration of nematode or insect cuticles $[2,10]$. In the study of Bonants et al., the subtilisin-like serine protease PSP-3 of nematode-parasitic fungus
Paecilomyces lilacinus was found to be involved in the infection of $P$. lilacinus against the eggs of the root-knot nematode Meloidogyne hapla [30].

Based on our bioassay results, we hypothesize that the subtilisin-like serine proteases secreted by entomopathogenic or nematode-parasitic fungi should be able to digest both the nematode and insect eggs. We therefore purified PSP-3 from P. lilacinus to test its ability to digest the nematode and insect eggs. As expected, our bioassay results showed that the amount of protein released into the supernatant in the protease treatment group (treatment a) was significantly higher than those with no protease (treatment b) or denatured protease (treatment c) (Figure 6; Additional file 5). After incubation with active subtilisin-like serine proteases, the eggshell of the root-knot nematode and the potato tuber moth were partially degraded, and some eggs were deformed (data not show), suggesting that the subtilisinlike serine protease produced by $P$. lilacinus degraded protein components of both nematode and insect eggs.

\section{Discussion and Conclusions}

Our study provides new insights into the evolution of subtilisin-like serine protease genes in Pezizomycotina. First, our phylogenetic results suggest that Pezizomycotina subtilisin-like serine proteases most likely evolved from endocellular to extracellular proteases. As seen from the tree, the subtilisin-like serine protease genes of Pezizomycotina previously identified or presumed to be endocellular proteases [5,25-28] were clustered into Clade $\mathrm{E}$ and diverged the earliest in the phylogeny. In contrast, most of those previously identified or presumed as extracellular proteases clustered into the other clades and diverged later. In addition, the protease (GenBank no. XM_001385908) from the outgroup Pichia stipitis was assumed as an endocellular protease [31], supporting the endocellular to extracellular

Table 2 Fungal strains used in the bioassay.

\begin{tabular}{|c|c|c|c|}
\hline YMF cultures (strain number) & Scientific Name & Pathogenicity & Reference(s) \\
\hline & Beauveria bassiana $^{a}$ & Entomopathogenic & {$[13,67,68]$} \\
\hline \multirow[t]{5}{*}{ YMF1.00112 } & Lecanicillium psalliotae $^{\mathrm{b}}$ & Nematophagous & {$[19,69,70]$} \\
\hline & Metarhizium anisopliae ${ }^{a}$ & Entomopathogenic & {$[71]$} \\
\hline & Metarhizium flavoviride $e^{c}$ & Entomopathogenic & {$[72,73]$} \\
\hline & Paecilomyces farinosus ${ }^{\mathrm{a}}$ & Entomopathogenic & {$[74,75]$} \\
\hline & Paecilomyces fumosoroseus ${ }^{a}$ & Entomopathogenic & {$[76,77]$} \\
\hline YMF1.00132 & Paecilomyces lilacinus ${ }^{\mathrm{b}}$ & Nematophagous & {$[78,79]$} \\
\hline YMF1.00130 & Pochonia chlamydosporia ${ }^{b}$ & Nematophagous & {$[80-82]$} \\
\hline YMF5.00245 & Nigrospora oryzae b, d & Phytopathogenic & {$[83]$} \\
\hline
\end{tabular}

\footnotetext{
a, Obtained from Prof. Zongqi Liang, Guiyang, Guizhou University, Guizhou Province, P. R. China.

b, Preserved in the Laboratory for Conservation and Utilization of Bio-resources, and Key Laboratory for Microbial Resources of the Ministry of Education, Yunnan University, Kunming, Yunnan Province, P. R. China.

c, Purchased from the Agricultural Culture Collection of China, Beijing, P. R. China.

${ }^{d}$, Used as the negative control.
} 

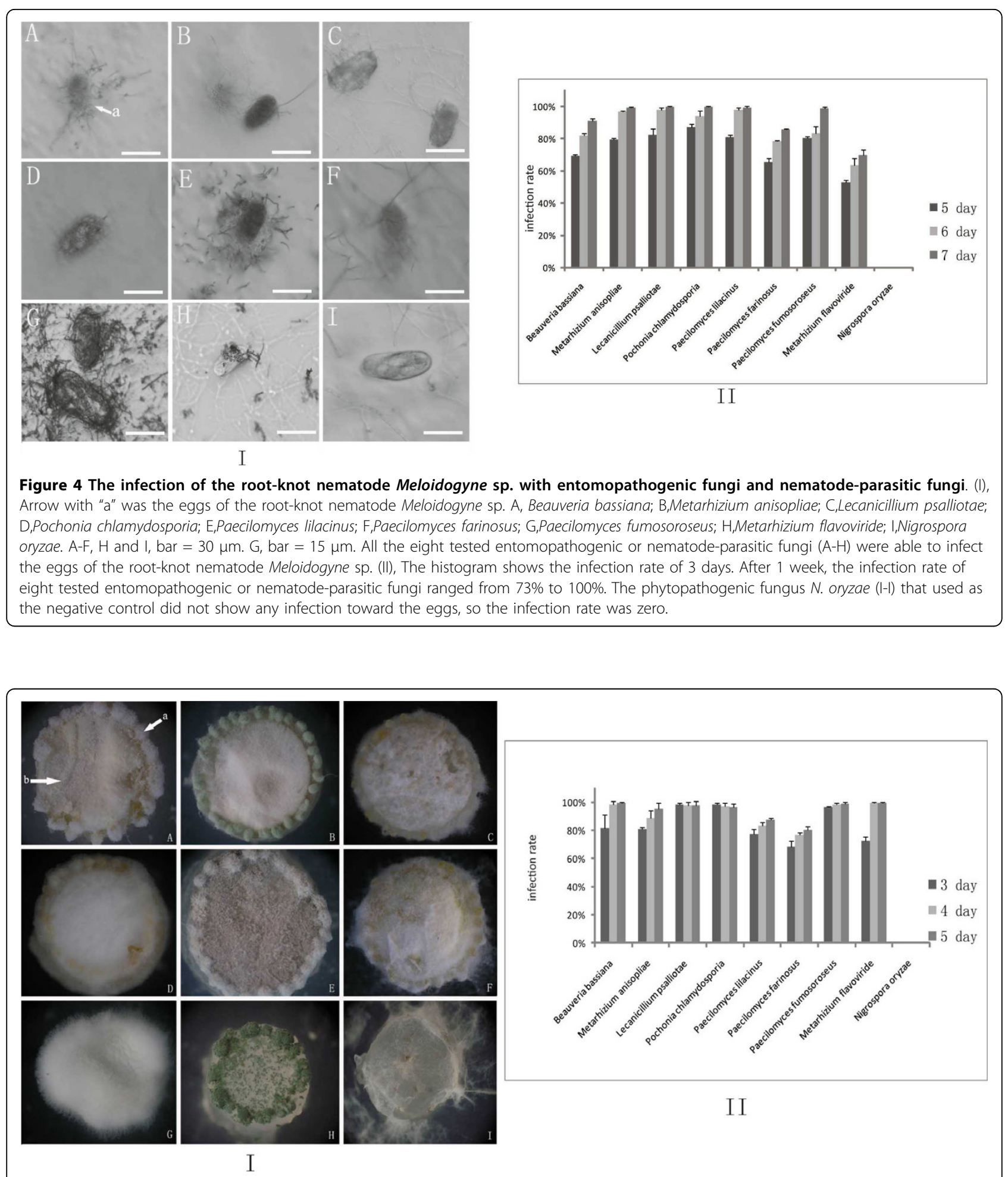

Figure 5 The infection of the potato tuber moth $P$. opercullella with entomopathogenic fungi and nematode-parasitic fungi. (I), Arrow with "a" was the eggs of potato tuber moth P. opercullella. Arrow with " $b$ " was the selected fungal strains. Strains A-I have been described in Figure 4. Each fungal culture is $6 \mathrm{~mm}$ in diameter. For the negative control (I-I) showed that all of the juveniles had hatched within 1 week. (II), Although the bioassay lasted for 1 week, the infection rate up to highest after 5 days later, so we only show the infection rate of 3-5 days. The infection rate of eight tested entomopathogenic or nematode-parasitic fungi ranged from $80 \%$ to $100 \%$. The phytopathogenic fungus N. oryzae $(I I-I)$ that used as the negative control did not show any infection toward the eggs and the juveniles were all hatched into juveniles within 5 days, so the infection rate was zero. 


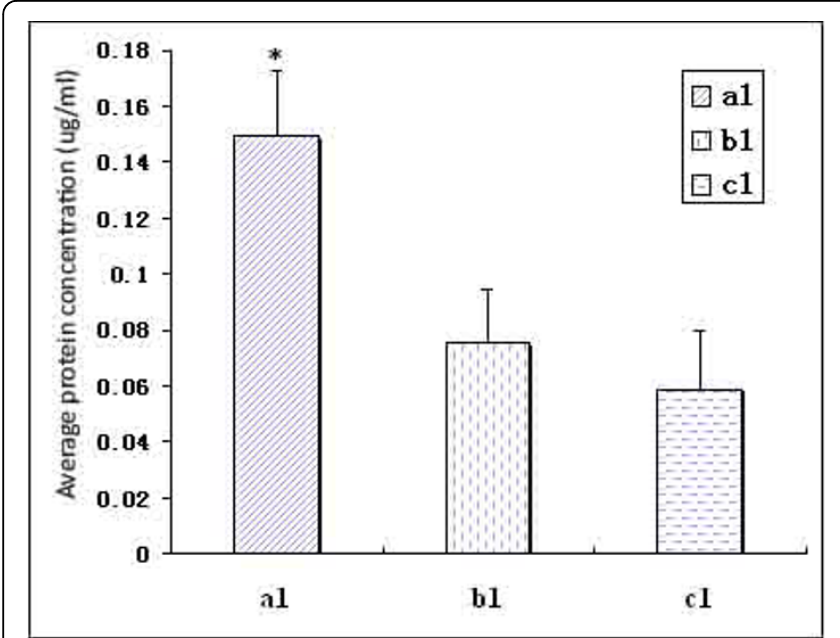

I

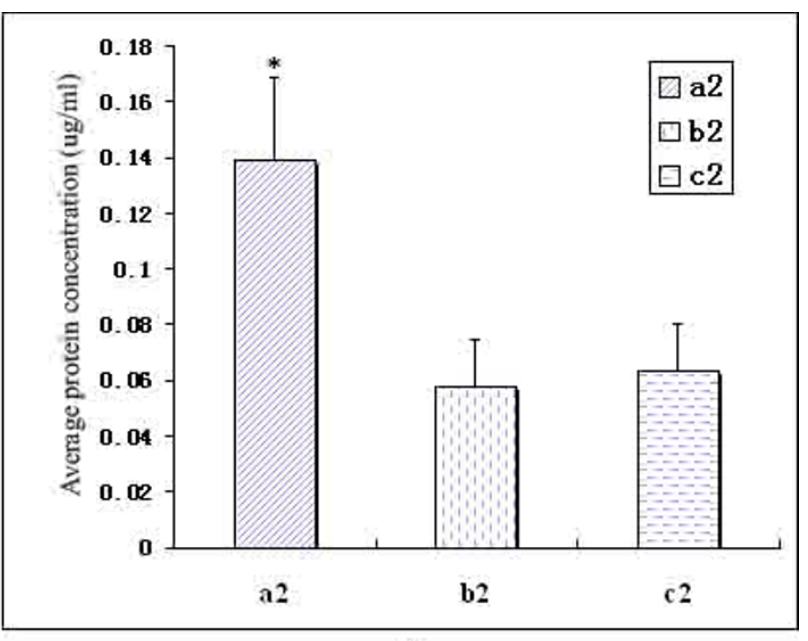

II

Figure 6 Effects of the subtilisin-like serine protease PSP-3 on the nematode and insect eggs. (I), Effect of the subtilisin-like serine protease PSP-3 produced by P. lilacinus on the eggs of the root-knot nematode Meloidogyne sp. The average amount of protein released into the supernatant of the treatment with the active protease (a1), none (b1) and denatured protease (c1); $\left(^{*}, P<0.05\right)$. (II), Effect of the subtilisin-like serine protease PSP-3 produced by P. lilacinus on the eggs of the potato tuber moth $P$. opercullella. The average amount of protein released into the supernatant of the treatment with the active protease (a2), none (b2) and denatured protease $\left.(c 2) ;{ }^{*}, P<0.05\right)$.

transition during the evolution of Pezizomycotina subtilisin-like serine proteases. The evolution from endocellular to extracellular enzymes might have facilitated pathogenic fungi to utilize these enzymes as virulence factor to colonize their hosts.

Second, our phylogenetic results and functional bioassays suggested that the entomopathogenic and nematode-parasitic fungi shared similar properties in parasitism. Previous studies indicated that the nematode-parasitic fungi could infect nematodes while the entomopathogenic fungi could parasitize other insects $[8,32]$. The grouping of the cuticle-degrading protease genes of these two groups of fungi led us to believe that they might have overlapping pathogenic mechanisms against both insects and nematodes. Further experimental bioassay showing that the entomopathogenic and nematode-parasitic fungi could infect both nematode and insect eggs supported this hypothesis (Figure 4 and 5). Moreover, the subtilisin-like serine protease PSP-3 produced by nematode-parasitic fungus $P$. lilacinus was observed to have the ability to digest the eggs of nematodes and insects (Figure 6; Additional file 5). Our finding enriches the known fungal resources for the microbial control of both types of pests.

Third, our data provide further understanding about the duplications and subsequent functional divergence of subtilisin-like serine protease genes in Pezizomycotina. Previous studies have shown that gene duplications occurred in subtilisin-like serine protease genes of pathogenic fungi and that such duplications might have played an essential role in pathogenicity and contributed to their increased adaptability, host range, and/or survived in various ecological habitats outside the host of these fungi [33].

From our phylogenetic tree, we found that frequent gene duplication events have occurred in many pathogenic fungi. For example, there were 9 paralogous subtilisin-like serine protease genes in Metarhizium anisopliae. Four of them, including PR1A, PR1B, PR1I and PR1G, clustered into Clade A with the other cuticle-degrading protease genes known to serve as important virulence factors during fungal penetration of nematode or insect cuticles $[13-17,19]$. These four genes most likely perform essential functions during the infection of hosts. In comparison, PR1J, PR1D, PR1E and $P R 1 F$ of $M$. anisopliae fell into Clade $C$, indicating that they might have diverged to perform different as yet uncharacterized functions. Our results are different from previous inferences suggesting that $P R 1 A$ was a key virulence factor during degradation of insect cuticles, while all the other PR1's were of only a minor contributor to cuticle degradation [25,34].

In the dermatophytic fungus Arthroderma benhamiae, there are 7 subtilisin-like serine protease genes (SUB1-7) [35]. Our phylogenetic tree clustered 6 of them in Clade B. The only exception was SUB2, which is grouped into Clade C. This result is consistent with the phylogeny of Jousson et al. [35]. They hypothesized that SUB2 was the most ancestral, while the other SUBs were dermatophyte-specific and might have emerged more recently through successive gene duplication events. In addition, they speculated that SUB3 and SUB4 were key virulence 
proteases of dermatophytes and playing important role in invasion of human or animal keratinised tissues [35]. From our analysis, the key virulence protease genes of dermatophytic fungi and nematophagous/entomopathogenic fungi were placed in different clades, suggesting that there were probably different pathogenic mechanisms between mammalian pathogens and nematode/ insect pathogens.

Fourth, our evolutionary analysis revealed signatures of positive selection acting on the subtilisin-like serine protease genes of the nematode-trapping fungi, suggesting that the subtilisin-like serine protease genes might have played important roles during the evolution of pathogenicity of nematode-trapping fungi against nematodes. Although they both belonged to the cuticledegrading proteases, the subtilisin-like serine protease genes from nematode-trapping fungi and nematodeparasitic fungi were not grouped together. This result supports earlier findings based on smaller data sets $[10,11,17]$. Since nematode-parasitic fungi do not produce trapping devices, they likely rely mainly on the extracellular enzymes (including subtilisin-like serine protease) as virulence factors to penetrate and digest nematode cuticles. In contrast, by virtue of synergistic interactions of extracellular enzymes and trapping devices, the nematode-trapping fungi can immobilize and penetrate nematodes within a few hours $[2,10]$. Therefore, the subtilisin-like serine proteases of nematode-trapping fungi might experience special selective pressure resulted from the co-evolution of trapping structures and proteolytic enzymes. Interestingly, our evolutionary analysis demonstrated evidence of positive selection acting on the cuticle-degrading protease genes in nematode-trapping fungi, at least during the early stage of its evolution. We hypothesize that the subtilisin-like serine protease genes may have played important roles during the evolution of pathogenicity of nematode-trapping fungi against nematodes. In addition, the potentially adaptive amino acid replacements discovered by our analysis will provide valuable information for functional analysis in future studies.

\section{Methods}

\section{Samples collection}

The five nematode-trapping fungi (Arthrobotrys yunnanensis YMF1.00593, Arthrobotrys musiformis YMF1.01043, Monacrosporium psychrophilum YMF1.01412, Monacrosporium coelobrochum YMF1.01480 and Dactylella shizishanna YMF1.00022) were isolated from field soil samples in Yunnan Province of China and permanently stored in the Yunnan Microbiological Fermentation Culture Collection Center (YMF). They were maintained on cornmeal agar (CMA) at $28^{\circ} \mathrm{C}$.

\section{Genomic DNA extraction}

The five nematode-trapping fungi were cultured in the PL-4 liquid medium on a rotary shaker $(150 \mathrm{rpm})$ at $28^{\circ}$ $\mathrm{C}$ for 1 week [36]. Their mycelia were then filtered on a nylon mesh and genomic DNA was isolated using the E. Z.N.A. ${ }^{@}$ Fungal DNA Mini kits (Omega Bio-Tek, Inc. USA) following the manufacturer's protocol.

\section{Primers design and cloning of subtilisin-like serine protease genes}

Degenerate primers (NP, NR, and P246) (Table 3) were designed based on previously reported six subtilisin-like serine protease genes from nematode-trapping fungi Arthrobotrys oligospora (GenBank no. X94121), Arthrobotrys conoides (GenBank no. AY859782), Monacrosporium microscaphoides (GenBank no. AY841167), Monacrosporium cystosporum (GenBank no. AY859780), Monacrosporium elegans (GenBank no. AY859781) and Dactylella varietas (GenBank no. DQ531603). NP and NR were used to amplify the full-length genes of subtilisin-like serine proteases from A. musiformis and A. yunnanensis, while P246 and NR were used to amplify the 3 '-end fragment of the genes from M. coelobrochum, $M$. psychrophilum and D. shizishanna. The primers 1480TSPN $(\mathrm{N}=1,2,3)$ and 22TSPN (Table 3), which were designed according to the amplified sequences of serine proteases, were respectively used to amplify the 5 '-end sequences from M. coelobrochum and D. shizishanna by using the DNA Walking Speedup ${ }^{\text {th }}$ PreMix Kit (Seegene, Korea) according to the user's manual.

The PCR reaction mixture was consisted of $0.5 \mu \mathrm{L}$ Taq DNA polymerase, $5 \mu \mathrm{L}$ of reaction mixture buffer, $3 \mu \mathrm{L}$ of $25 \mathrm{mM} \mathrm{MgCl} 2,1 \mu \mathrm{L}$ of $2.5 \mathrm{mM}$ dNTPs, $1 \mu \mathrm{L}$ of $100 \mu \mathrm{M}$ degenerate primers, $3 \mu \mathrm{L}$ of DNA template in a final volume of $50 \mu \mathrm{L}$ supplied with double-distilled sterile water. Amplification started at $95^{\circ} \mathrm{C}$ for $5 \mathrm{~min}$,

Table 3 List of primers used in this study.

\begin{tabular}{ll}
\hline Primer & Primer Sequence \\
\hline NP & 5-AATG(A/C)T(G/T)(A/T)(C/T)GAACGGCCT(C/T)A-3 \\
NR & 5-TTAAGC(G/A)(G/T)(A/T/C)(G/T)CC(G/A)TTGTAG-3 \\
P246 & 5-AA(G/A)TA(C/T)AT(C/T)GTCGTC(C/T)(A/T)(C/G)AAG-3 \\
1480TSP1 & 5-ATGAGAGATGCGGTCAAGGC-3 \\
1480TSP2 & 5-CGACTTCAGGCGAGTTCAGAATC-3 \\
1480TSP3 & 5-CAAAGCCGCCAGTGTATCCAG-3 \\
22TSP1 & 5-TGAGAGATGCGGTCAAGAC-3 \\
22TSP2 & 5-TATCCTGAAGAGTAGCAGCGTCG-3 \\
22TSP3 & 5-GGCGTGGAGAGATGAATGCG-3 \\
\hline
\end{tabular}

NP and NR were used to amplify the full-length encoding genes of subtilisinlike serine proteases from A. musiformis and A. yunnanensis. P246 and NR were used to amplify the $3^{\prime}$ fragment of the subtilisin-like serine protease genes from M. coelobrochum, M. psychrophilum and D. shizishanna. 1480TSPN $(\mathrm{N}=1,2,3)$ and 22TSPN $(\mathrm{N}=1,2,3)$ were used to amplify the $5^{\prime}$ fragment sequences from $M$. coelobrochum and D. shizishanna by using the DNA Walking Speedup ${ }^{\text {TM }}$ PreMix Kit (Seegene, Korea), respectively 
followed by 35 cycles with $95^{\circ} \mathrm{C}$ for $40 \mathrm{~s}, 51^{\circ} \mathrm{C}$ for $40 \mathrm{~s}$, and $72^{\circ} \mathrm{C}$ for $1.5 \mathrm{~min}$. After the last cycle, the reaction mixture was maintained at $72^{\circ} \mathrm{C}$ for $10 \mathrm{~min}$ for a final extension step.

\section{Sequencing and sequence analysis}

The amplified products were electrophoresed on $1 \%$ agarose gels to check for fragment size and purity. All the PCR products were purified using the DNA fragment purification kit ver 2.0 (Takara, Japan) and subcloned into the vector pMD18-T (Takara, Japan). Escherichia coli strain DH5 $\alpha$ was used as a host for transformation and cloning. It was grown in Luria-Bertani medium at $37^{\circ} \mathrm{C}$. Ten positive colonies were selected for sequencing from each strain. The plasmids were sequenced in both directions on an ABI 3730 automated sequencer (Perkin-Elmer, USA). Sequence assembly was performed using the SeqMan software (DNA Star software package, DNASTAR, Inc. USA) and DNAman software package (Version 5.2.2, Lynnon Biosoft, Canada). Signal sequence was predicted using SignalP [37]http://www.cbs.dtu.dk/services/SignalP/. Protein molecular masses were determined online with ProtParam tools http://us.expasy.org/tools/protparam.html, and $\mathrm{N}$-linked glycosylation sites were predicted by NetNGlyc http://www.cbs.dtu.dk/services/NetNGlyc/.

\section{Subtilisin-like serine protease genes from the other Pezizomycotina species}

The amino acid sequences of each protease characterized as members of the subtilisin-like family were retrieved from National Center for Biotechnology Information (NCBI) [38] using BLASTX [39]. MEROPS and UniProtKB (UniProt Knowledgebase) protein sequence database were also screened to iteratively search all known and predicted subtilisin-like serine protease genes, making sure that all available subtilisin-like serine protease genes of Pezizomycotina were included in the analyses. A total of nearly 500 subtilisin-like serine protease genes representing five of nine classes in Pezizomycotina, including Sordariomycetes, Eurotiomycetes, Leotiomycetes, Dothideomycetes and Orbiliomycetes, were obtained. In addition, five subtilisin-like serine protease genes from fungi in the Saccharomycotina were downloaded and used as outgroups. The partial sequences and those with unusual lengths $(<200$ aa or $>700 \mathrm{aa}$ ) in Pezizomycotina were removed from the analysis, yielding 287 sequences.

The amino acids sequences of the 287 genes were aligned using Clustal X version 1.83 [40] with default parameters. Several sequences with ambiguously aligned regions around the three active catalytic residues (AspHis-Ser) and those with identical sequences but different accession numbers were eliminated in the analysis, yielding 189 subtilisin-like sequences in the final dataset. The Gblocks program http://molevol.cmima.csic.es/castresana/Gblocks.html[41,42] was applied to extract conserved regions that contain more reliable phylogenetic signals. An alignment consisting of 229 amino acid positions was obtained.

\section{Phylogenetic analysis}

Four tree-building methods were performed for phylogenetic reconstructions. The maximum parsimony (MP) tree with heuristic search was constructed using PAUP*4.0b8 [43], and maximum likelihood (ML) tree with the best-fit model (WAG+I+G) was constructed using PHYML version 2.4.4 [44]. The best-fit model of protein evolution was selected by ProtTest http://darwin.uvigo.es[45]. In addition, the program MEGA 4.1 $[46,47]$ was used to construct a neighbor joining (NJ) tree [48] and MrBayes 3.1.2 [49] was used to perform Bayesian analysis. Bayesian analysis started with randomly generated trees and four Markov chains under default heating values were ran for $2 \times 10^{6}$ generations, with sampling at intervals of 100 generations. To ensure that these analyses were not trapped in local optima, the dataset was run three times independently. We determined the burn-in period by checking for likelihood stability.

To test for nodal reliabilities, bootstrap (BS) analysis [50] for MP (1,000 replicates), ML (100 replicates) and NJ (1,000 replicates) was applied. Bayesian posterior probabilities (PP) from the $50 \%$ majority-rule consensus tree were calculated to provide the estimates of nodal support in Bayesian phylogenies.

\section{Testing the inconsistency of tree topologies}

AU-test [51], SH-test [52] and $\mathrm{KH}$-test [53] were performed using CONSEL version $0.1 \mathrm{~h}$ [54] with site-wise log-likelihoods calculated by Tree-Puzzle 5.1 [55] to assess the inconsistency of tree topologies.

\section{Detecting positive selection in nematode-trapping fungi}

Positive selection has been considered a major force in forming new motifs or functions in proteins [56]. The non-synonymous to synonymous rate ratio $\omega$ $(d \mathrm{~N} / d \mathrm{~S})$ provides an indication of the change in selective pressures. A $d \mathrm{~N} / d \mathrm{~S}$ ratio $=1,<1$, and $>1$ indicates neutral evolution, purifying selection, and positive selection on the protein involved, respectively. In this study, CODEML program of the PAML package $[57,58]$ and the Bn-Bs software http://www. bio.psu.edu/People/Faculty/Nei/Lab/software.htm[59] were implemented to detect signatures of positive selection in nematode-trapping fungi. The multiply aligned data are available as supplementary material (see Additional file 6). 
The Bn-Bs software implements a modified method from the original [60] by taking into account the transition bias for estimating synonymous and nonsynonymous substitutions along the branches of a given tree. Here, one-tailed $\mathrm{Z}$ test was performed.

Considering that positive selection may act in very short episodes during the evolution of a protein [61] and affect only a few sites along a few lineages in the phylogeny, the "branch-site" model, which allows $\omega$ ratios to vary both among lineages of interest and amino acid sites, was considered here in codon-based likelihood analysis using the PAML software $[57,58]$. We used the branch-site Model A as a stringent test to identify the sites under positive selection along the lineages of interest [62] and each model was run twice. All the possible tree topologies were used here.

\section{The infection of insects and nematodes with entomopathogenic fungi and nematode-parasitic fungi}

For bioassays against the root-knot nematode, nine selected fungi (Table 2) were cultivated in 9 sterile Water Agar (WA) media (15 g agar in $1 \mathrm{~L}$ deionized water) at room temperature $\left(10-25^{\circ} \mathrm{C}\right)$ separately, until each agar medium surface was colonized by the fungus. Then a suspension of nematode eggs (ca. 400 eggs) was added onto the fungal culture and the mixture was then kept at the room temperature. In order to keep the eggs moisturized, a $200 \mu \mathrm{L}$ sterile M9 buffer $\left(\mathrm{Na}_{2} \mathrm{HPO}_{4} 6 \mathrm{~g}\right.$, $\mathrm{KH}_{2} \mathrm{PO}_{4} 3 \mathrm{~g}, \mathrm{NaCl} 0.5 \mathrm{~g}, \mathrm{NH}_{4} \mathrm{Cl} 1 \mathrm{~g}$, deionized water to $1 \mathrm{~L})$ was added daily. After 5 days, each culture was observed daily with the Olympus BX51 microscope (Japan) and counted the infected eggs 3 times each day. The criterion of infection was that the root-knot nematode eggs were failed to hatch and the fungal mycelia were seen growing from the eggs, while none could be seen in the negative control. All assays were repeated 3 times and each replicates lasted a week.

For bioassays against the potato tuber moth, a fungal culture with $6 \mathrm{~mm}$ in diameter was inoculated onto the center of a WA medium. Then exactly 30 insect eggs were put on the periphery of the fungal culture and incubated at room temperature. From 3 days onward, each culture was observed daily and counted the infected eggs 3 times each day. The criterion of infection was that the potato tuber moth eggs were failed to hatch and the fungal mycelia were seen growing from the eggs. All assays were repeated 3 times and each replicate lasted for 1 week.

\section{Effects of the subtilisin-like serine protease PSP-3 on the nematode and insect eggs}

The subtilisin-like serine protease PSP-3 produced by the nematophagous fungus $P$. lilacinus was tested for its ability to degrade the eggs of the root-knot nematode
Meloidogyne sp. and potato tuber moth $P$. opercullella. The protease PSP-3 was purified following the procedures described by Bonants et al. [30].

The following experiment design was used: (treatment a). nematode (a1) or insect (a2) eggs, protease $(1,000$ $\mu \mathrm{g} / \mathrm{mL}, 0.2 \mathrm{U} / \mathrm{mL}$, dissolved in potassium phosphate buffer) $10 \mu \mathrm{L}$, toluene (as an antiseptic) $3 \mu \mathrm{L}$, potassium phosphate buffer $(0.1 \mathrm{~mol} / \mathrm{L}) 137 \mu \mathrm{L}$; (treatment b). nematode (b1) or insect (b2) eggs, toluene $3 \mu \mathrm{L}$, potassium phosphate buffer $(0.1 \mathrm{~mol} / \mathrm{L}) 147 \mu \mathrm{L}$; (treatment c). nematode (c1) or insect (c2) eggs, denatured protease $(1,000 \mu \mathrm{g} / \mathrm{mL}, 0.2 \mathrm{U} / \mathrm{mL}$, dissolved in potassium phosphate buffer and then denatured by boiling for $30 \mathrm{~min}$ ) $10 \mu \mathrm{L}$, toluene $3 \mu \mathrm{L}$, potassium phosphate buffer $(0.1$ $\mathrm{mol} / \mathrm{L}) 137 \mu \mathrm{L}$; and $(\mathrm{d})$. toluene $3 \mu \mathrm{L}$, potassium phosphate buffer $(0.1 \mathrm{~mol} / \mathrm{L}) 147 \mu \mathrm{L}$. Protein concentration was measured using Coomassie Brilliant Blue G-250 according to Bradford [63], with bovine serum albumin $(25-400 \mu \mathrm{g} / \mathrm{mL})$ as the standard. One unit of protease was defined as the amount of enzyme that released 1 $\mathrm{mg}$ tyrosine $/ \mathrm{min}$ at $25^{\circ} \mathrm{C}$. For the nematode assay, $\mathrm{ca}$. 1700 eggs were used in each treatment. For the insect assay, exactly 30 eggs were used. All the treatments were shaken at Speed 3 on the mixer (Cole-Parmer, USA) at $25^{\circ} \mathrm{C}$. Every $24 \mathrm{~h}$, each treatment was precipitated and a $20 \mu \mathrm{L}$ - supernatant was collected to measure the amount of protein concentration using casein as substrate. The supernatant from treatment (d) was used as the negative control. Whole assay was repeated 3 times. After checking the data with the KolmogorovSmirnov test and Shapiro-Wilk test [64-66], we found the data from each treatment are approximated a normal distribution $(P \geq 0.05)$ (see Additional file 7). Statistics analyses were then carried out using one-way analysis of variance (ANOVA) in SPSS 14.0. Moreover, the LSD-test was also used for pairwise comparisons among the three treatments (see Additional file 5). A $P$ value of less than 0.05 was considered as statistically significant.

\footnotetext{
Additional file 1: MP tree. The MP tree with heuristic search was constructed using PAUP*4.0b8 [43] with 1,000 replicates. Click here for file

[http://www.biomedcentral.com/content/supplementary/1471-2148-1068-S1.JPEG ]

Additional file 2: $\mathbf{N} \boldsymbol{J}$ tree. The program MEGA 4.1[46,47] was used to construct a neighbor joining (NJ) tree with 1,000 replicates. Click here for file

[http://www.biomedcentral.com/content/supplementary/1471-2148-1068-S2.JPEG ]

Additional file 3: $\mathrm{ML}$ tree. The ML tree with the best-fit model (WAG+I $+G$ ) was constructed using PHYML version 2.4.4 [44]. The best-fit model of protein evolution was selected by ProtTest http://darwin.uvigo.es[45] Click here for file

[http://www.biomedcentral.com/content/supplementary/1471-2148-1068-S3.JPEG ]
} 
Additional file 4: Evidence of adaptive evolution from branch-site model analysis for cuticle-degrading protease genes from nematode-trapping fungi. The branch-site model analysis using CODEML program of the PAML package $[57,58]$ was used to detect signatures of positive selection in the cuticle-degrading proteases from nematode-trapping fungi. Six branches (designated as $a-f$ ) showed signs of significant positive selection in all four tree topologies. Several positively selected residues were also identified for these branches with high posterior probabilities. ${ }^{a}$, After Bonferroni correction for multiple testing, branches $b, e$ and $f$ are still significant of all four tree topologies. b, In $L$ is the log-likelihood scores. ${ }^{c}$, LRT to detect adaptive evolution. ${ }^{* * *} P<0.001 ;{ }^{*} 0.001<P<0.01 ;{ }^{*} 0.01<P<0.05$. ${ }^{d}$, Those codons with posterior probabilities $>99 \%$ are shown in boldface.

Click here for file

[http://www.biomedcentral.com/content/supplementary/1471-2148-1068-S4.DOCX]

Additional file 5: Results of one-way analysis of variance (ANOVA) and LSD-test using SPSS 14.0. The data of each treatment were carried out using one-way analysis of variance (ANOVA) in SPSS 14.0. Moreover, the LSD-test was also used for pairwise comparisons among the three treatments. A $P$ value of less than 0.05 was considered as statistically significant. The results showed that the average amount of protein released into the supernatant in the protease treatment group (treatment a) was significantly higher than those with no protease (treatment b) or denatured protease (treatment c). I', The subtilisin-like serine protease PSP-3 produced by P. lilacinus on the eggs of the rootknot nematode Meloidogyne sp. $\|^{b}$, The subtilisin-like serine protease PSP3 produced by $P$. lilacinus on the eggs of the potato tuber moth $P$. opercullella.

Click here for file

[http://www.biomedcentral.com/content/supplementary/1471-2148-1068-S5.DOCX]

Additional file 6: Multiple nucleotide alignment results used to do positive selection analysis. The nucleotide sequences were translated to amino acids and aligned using MUSCLE Version 3.7 [84]. The alignment was then used to extract the conserved alignment regions using the Gblocks program http://molevol.cmima.csic.es/castresana/ Gblocks.html[40,41]. Finally, 792 conserved nucleotide sites were obtained.

Click here for file

[http://www.biomedcentral.com/content/supplementary/1471-2148-1068-S6.FAST]

\section{Additional file 7: Detection of normal distribution with the} Kolmogorov-Smirnov test and Shapiro-Wilk test in SPSS 14.0. The 18 data points of each treatment were checked for normal distribution with Kolmogorov-Smirnov test and Shapiro-Wilk test [64-66] in SPSS 14.0. The results showed that the data from the three treatments all approximated a normal distribution $(P \geq 0.05)$. ${ }^{a}$, The subtilisin-like serine protease PSP3 produced by $P$. lilacinus on the eggs of the root-knot nematode Meloidogyne sp. $\|^{b}$, The subtilisin-like serine protease PSP-3 produced by $P$. lilacinus on the eggs of the potato tuber moth $P$. opercullella.

Click here for file

[http://www.biomedcentral.com/content/supplementary/1471-2148-1068-S7.DOCX]

\section{Acknowledgements}

We thank Dr. Jianping Xu (McMaster University, Canada), Jianjun Gao, Shuqun Liu and Mrs. Wei Zhou for their help and advice in our experiment. This work was funded by National Basic Research Program of China (approved no. 2007CB411600), projects from National Natural Science Foundation of China (approved nos. 30630003, 30660107 and 30960229). and the Department of Science and Technology of Yunnan province (approved nos. 2007C007Z, 2005NG05 and 2009C1052).

\section{Author details}

'Laboratory for Conservation and Utilization of Bio-resources, and Key Laboratory for Microbial Resources of the Ministry of Education, Yunnan
University, Kunming, 650091, PR China. ${ }^{2}$ Institute of Environment Sciences and Lakes Research, Yunnan University, Kunming, 650091, PR China. ${ }^{3}$ Engineering Research Center of Industrial Microbiology of Ministry of Education, Fujian Normal University, Fuzhou, 350108, PR China. ${ }^{4}$ School of Life Sciences, Yunnan Normal University, Kunming, 650092, PR China.

\section{Authors' contributions}

$J L, L Y, J Y$, and $K Z$ conceived this study. $J L$ and LD conducted all experimental work. JL collected data, carried out analyses and wrote the draft manuscript. LY and BT contributed to data analyses. JY and LY contributed to manuscript revisions. All other authors helped in interpretation of data and discussion of results. All authors read and approved the manuscript.

Received: 11 August 2009 Accepted: 9 March 2010

Published: 9 March 2010

\section{References}

1. Walton JD: Host-selective toxins: agents of compatibility. Plant Cell 1996, 8:1723-1733

2. Huang XW, Zhao NH, Zhang KQ: Extracellular enzymes serving as virulence factors in nematophagous fungi involved in infection of the host. Res Microbiol 2004, 155:811-816.

3. St Leger RJ: The role of cuticle-degrading proteases in fungal pathogenesis of insects. Can J Bot 1995, 73:1119-1125.

4. Sreedhar L, Kobayashi DY, Bunting TE, Hillman BI, Belanger FC: Fungal proteinase expression in the interaction of the plant pathogen Magnaporthe poae with its host. Gene 1999, 235:121-129.

5. Bryant MK, Schardl CL, Hesse U, Scott B: Evolution of a subtilisin-like protease gene family in the grass endophytic fungus Epichloë festucae. BMC Evol Biol 2009, 9:168.

6. Spatafora JW, Johnson D, Sung GH, (33, co-authors), et al: A five-gene phylogenetic analysis of the Pezizomycotina. Mycologia 2006, 98:1020-1030.

7. James TY, Kauff F, Schoch CL, (70, co-authors), et al: Reconstructing the early evolution of fungi using a six-gene phylogeny. Nature 2006, 443:818-822.

8. Barron GL: The nematode-destroying fungi. Topics in Mycobiology 1 Canada: Canadian Biological Publications 1977, 140.

9. Pfister DH: Orbilia fmicola, a nematophagous discomycetes and its Arthrobotrys anamorph. Mycologia 1994, 86:451-453.

10. Yang JK, Tian BY, Liang LM, Zhang KQ: Extracellular enzymes and the pathogenesis of nematophagous fungi. Appl Microbiol Biotechnol 2007, 75:21-31.

11. Åhman J, Ek B, Rask L, Tunlid A: Sequence analysis and regulation of a gene encoding a cuticle-degrading serine protease from the nematophagous fungus Arthrobotrys oligospora. Microbiology 1996, 142:1605-1616.

12. Wang M, Yang JK, Zhang KQ: Characterization of an extracellular protease and its CDNA from the nematode-trapping fungus Monacrosporium microscaphoides. Can J Microbiol 2006, 52:130-139.

13. Joshi L, St Leger RJ, Bidochka MJ: Cloning of a cuticle-degrading protease from the entomopathogenic fungus, Beauveria bassiana. FEMS Microbiol Lett 1995, 125:211-217.

14. Morton CO, Hirsch PR, Peberdy JP, Kerry BR: Cloning of and genetic variation in protease VCP1 from the nematophagous fungus Pochonia chlamydosporia. Mycol Res 2003, 107:38-46.

15. Sheng JZ, Kun A, Deng CS, Li WJ, Bao XM, Qiu DW: Cloning a cuticledegrading serine protease gene with biological control function from Beauveria brongniartii and its expression in Escherichia coli. Curr Microbiol 2006, 53:124-128.

16. St Leger RJ, Frank DC, Roberts DW, Staples RC: Molecular cloning and regulatory analysis of the cuticle-degrading protease structural gene from the entomopathogenic fungus Metarhizium anisopliae. Eur $J$ Biochem 1992, 204:991-1001.

17. Wang B, Liu X, Wu W, Liu X, Li S: Purification, characterization, and gene cloning of an alkaline serine protease from a highly virulent strain of the nematode-endoparasitic fungus Hirsutella rhossiliensis. Microbiol Res 2009, 164:665-673.

18. Wang RB, Yang JK, Lin C, Zhang Y, Zhang KQ: Purification and characterization of an extracellular serine protease from the nematode- 
trapping fungus Dactylella shizishanna. Lett Appl Microbiol 2006, 42:589-594.

19. Yang JK, Huang XW, Tian BY, Wang M, Niu QH, Zhang KQ: Isolation and characterization of a serine protease from the nematophagous fungus, Lecanicillium psalliotae, displaying nematicidal activity. Biotechnol Lett 2005, 27:1123-1128.

20. Yang JK, Li J, Liang LM, Tian BY, Zhang Y, Chen CM, Zhang KQ: Cloning and characterization of a cuticle-degrading protease from the nematode-trapping fungus Arthrobotrys conoides. Arch Microbiol 2007, 188:167-174

21. Yang JK, Liang LM, Zhang Y, Li J, Zhang L, Ye FP, Zhang KQ: Purification and cloning of a novel serine protease from the nematode-trapping fungus Dactylellina varietas and its potential roles in infection against nematodes. Appl Microbiol Biotechnol 2007, 75:557-565.

22. Zhao ML, Mo MH, Zhang KQ: Characterization of a neutral serine protease and its full-length CDNA from the nematode-trapping fungus Arthrobotrys oligospora. Mycologia 2004, 96:16-22.

23. Zhang YJ, Liu XZ, Wang M: Cloning, expression, and characterization of two novel cuticle-degrading serine proteases from the entomopathogenic fungus, Cordyceps sinensis. Res Microbiol 2008, 159:462-469.

24. Betzel C, Pal GP, Saenger W: Three-dimensional structure of proteinase $K$ at 0.15-nm resolution. Eur J Biochem 1988, 178:155-171.

25. Bagga S, Hu G, Screen SE, St Leger RJ: Reconstructing the diversification of subtilisins in the pathogenic fungus Metarhizium anisopliae. Gene 2004, 324:159-169.

26. Fukiya S, Kuge T, Tanishima T, Sone T, Kamakura T, Yamaguchi I, Tomita F: Identification of a putative vacuolar serine protease gene in the rice blast fungus, Magnaporthe grisea. Biosci Biotechnol Biochem 2002, 66:663-666.

27. Shen HD, Wang CW, Lin WL, Lai HY, Tam MF, Chou H, Wang SR, Han SH: CDNA cloning and immunological characterization of Pen o 18, the vacuolar serine protease Major llergen from Penicillium oxalicum. J Lab Clin Med 2001, 137:115-124.

28. Yu CJ, Chen YM, Su SN, Forouhar F, Lee SH, Chow LP: Molecular and immunological characterization and lgE epitope mapping of Pen $n$ 18, a major allergen of Penicillium notatum. Biochem J 2002, 363:707-715.

29. Nakagawa S: A farewell to Bonferroni: the problems of low statistical power and publication bias. Behav Ecol 2004, 15:1044-1045.

30. Bonants PJ, Fitters PF, Thijs $\mathrm{H}$, den Belder E, Waalwijk C, Henfling JW: A basic serine protease from Paecilomyces lilacinus with biological activity against Meloidogyne hapla eggs. Microbiology 1995, 141:775-784.

31. Jeffries TW, Grigoriev IV, Grimwood J, (13, co-authors), et al: Genome sequence of the lignocellulose-bioconverting and xylose-fermenting yeast Pichia stipitis. Nature 2007, 25:319-326.

32. Poinar GO: Entomophagous Nematodes. Biological Plant and Health Protection New York: StuttgartFranz JM 1986, 95-121.

33. Hu G, St Leger RJ: A phylogenomic approach to reconstructing the diversification of serine proteases in fungi. J Evol Biol 2004, 17:1204-1214.

34. St Leger RJ, Butt TM, Staples RC, Roberts DW: Synthesis of proteins including a cuticle-degrading protease during differentiation of the entomopathogenic fungus Metarhizium anisopliae. Exp Mycol 1989, 13:253-262.

35. Jousson O, Lechenne B, Bontems O, Mignon B, Reichard U, Barblan J, Quadroni M, Monod M: Secreted subtilisin gene family in Trichophyton rubrum. Gene 2004, 339:79-88.

36. Luo H, Mo MH, Huang XW, Li X, Zhang KQ: Coprinus comatus: a basidiomycete fungus forms novel structures and infects nematode. Mycologia 2004, 96:1218-1225.

37. Bendtsen JD, Nielsen $H$, Von Heijne G, Brunak S: Improved prediction of signal peptides: SignalP 3.0. J Mol Biol 2004, 340:783-795.

38. Wheeler DL, Barrett T, Benson DA, (29, co-authors), et al: Database resources of the National Center for Biotechnology Information. Nucl Acids Res 2005, 33:39-45.

39. Altschul SF, Gish W, Miller W, Myers EW, Lipman DJ: Basic local alignment search tool. J Mol Biol 1990, 215:403-410.

40. Thompson JD, Gibson TJ, Plewniak F, Jeanmougin F, Higgins DG: he CLUSTAL_X windows interface: flexible strategies for multiple sequence alignment aided by quality analysis tools. Nucl Acids Res 1997, 25: T4876-4882.
41. Castresana J: Selection of conserved blocks from multiple alignments for their use in phylogenetic analysis. Mol Biol Evol 2000, 17:540-552.

42. Talavera G, Castresana J: Improvement of phylogenies after removing divergent and ambiguously aligned blocks from protein sequence alignments. Syst Biol 2007, 56:564-577.

43. Swofford DL: PAUP*: phylogenetic analysis using parsimony (* and other methods). Version 4.0b8. Sunderland, MA: Sinauer Associates 2002.

44. Guindon S, Gascuel O: A simple, fast, and accurate algorithm to estimate large phylogenies by maximum likelihood. Syst Bio 2003, 52:696-704.

45. Abascal F, Zardoya R, Posada D: ProtTest: selection of best-fit models of protein evolution. Bioinformatics 2005, 21:2104-2105.

46. Tamura K, Dudley J, Nei M, Kumar S: MEGA4: Molecular Evolutionary Genetics Analysis (MEGA) software version 4.0. Mol Biol Evol 2007, 24:1596-1599.

47. Kumar S, Nei M, Dudley J, Tamura K: MEGA: a biologist-centric software for evolutionary analysis of DNA and protein sequences. Brief Bioinform 2008, 9:299-306

48. Tamura K, Nei M: Estimation of the number of nucleotide substitutions in the control region of mitochondrial DNA in humans and chimpanzees. Mol Biol Evol 1993, 10:512-526.

49. Ronquist F, Huelsenbeck JP: MrBayes 3: Bayesian phylogenetic inference under mixed models. Bioinformatics 2003, 19:1572-1574.

50. Felsenstein J: Confidence limits on phylogenies: an approach using the bootstrap. Evolution 1985, 39:783-791

51. Shimodaira $\mathrm{H}:$ An approximately unbiased test of phylogenetic tree selection. Syst Biol 2002, 51:492-508.

52. Shimodaira H, Hasegawa M: Multiple comparisons of log-likelihoods with applications to phylogenetic inference. Mol Biol Evol 1999, 16:1114-1116.

53. Kishino $\mathrm{H}$, Hasegawa M: Evaluation of the maximum likelihood estimate of the evolutionary tree topologies from DNA sequence data, and the branching order in Hominoidea. J Mol Evol 1989, 29:170-179.

54. Shimodaira $H$, Hasegawa M: CONSEL: for assessing the confidence of phylogenetic tree selection. Bioinformatics 2001, 17:1246-1247.

55. Schmidt HA, Strimmer K, Vingron M, von Haeseler A: TREE-PUZZLE: maximum likelihood phylogenetic analysis using quartets and parallel computing. Boinformatics 2002, 18:502-504.

56. Yang Z, Nielsen R: Codon-substitution models for detecting molecular adaptation at individual sites along specific lineages. Mol Biol Evol 2002, 19:908-917.

57. Yang Z: PAML: a program package for phylogenetic analysis by maximum likelihood. Comput Appl Biosci 1997, 13:555-556.

58. Yang Z: PAML 4: Phylogenetic analysis by maximum likelihood. Mol Biol Evol 2007, 24:1586-1591.

59. Zhang J, Rosenberg HF, Nei M: Positive Darwinian selection after gene duplication in primate ribonuclease genes. Proc Natl Acad Sci USA 1998, 95:3708-3713.

60. Nei M, Gojobori T: Simple methods for estimating the numbers of synonymous and nonsynonymous nucleotide substitutions. Mol Biol Evol 1986, 3:418-426.

61. Gillespie JH: The causes of molecular evolution. Oxford: Oxford University Press 1991.

62. Zhang J, Nielsen R, Yang Z: Evaluation of an improved branch-site likelihood method for detecting positive selection at the molecular level. Mol Biol Evol 2005, 22:2472-2479.

63. Bradford MM: A rapid and sensitive method for the quantitation of microgram quantities of protein utilizing the principle of protein-dye binding. Anal Biochem 1976, 72:248-254

64. Fasano G, Franceschini A: A multidimensional version of the KolmogorovSmirnov test. Monthly Notices of the Royal Astronomical Society 1987, 225:155-170.

65. Lopes RHC, Reid I, Hobson PR: The two-dimensional Kolmogorov-Smirnov test. XI International Workshop on Advanced Computing and Analysis Techniques in Physics Research Netherlands: Amsterdam 2007.

66. Shapiro SS, Wilk MB: An analysis of variance test for normality (complete samples). Biometrika 1965, 52:591-611.

67. Hegedus DD, Bidochka MJ, Miranpuri GS, Khachatourians GG: A comparison of the virulence, stability and cell-wall-surface characteristics of three spore types produced by the entomopathogenic fungus Beauveria bassiana. Appl Microbiol Biotechnol 1992, 36:785-789. 
68. Kouassi M, Coderre D, Todorova SI: Effects of the timing of applications on the incompatibility of three fungicides and one isolate of the entomopathogenic fungus Beauveria bassiana (Balsamo) Vuillemin (Deuteromycotina). J Appl Ent 2003, 127:421-426.

69. Steenberg T, Humber RA: Entomopathogenic potential of Verticillium and Acremonium species (Deuteromycotina: Hyphomycetes). J Invertebr Pathol 1999, 3:309-314.

70. Asensio L, Lopez-Llorca LV, López-Jiménez JA: Use of light, scanning electron microscopy and bioassays to evaluate parasitism by entomopathogenic fungi of the red scale insect of palms (Phoenicococcus marlatti Ckll., 1899). Micron 2005, 36:169-175.

71. Renn N, Bywater AF, Barson G: A bait formulated with Metarhizium anisopliae for the control of Musca domestica L. (Dipt., Muscidae) assessed in large-scale laboratory enclosures. J Appl Ent 1999, 123:309-314.

72. Welling M, Nachtigall G, Zimmermann G: Metarhizium spp. isolates from madagascar: morphology and effect of high temperature on growth and infectivity to the migratory locust, Locusta migratoria. Entomophaga 1994, 39:351-361.

73. Fargues J, Smits N, Vidal C, Vey A, Vega F, Mercadier G, Quimby P: Effect of liquid culture media on morphology, growth, propagule production, and pathogenic activity of the Hyphomycete, Metarhizium flavoviride. Mycopathologia 2001, 54:127-138.

74. Prenerová E: Pathogenicity of Paecilomyces farinosus toward Cephalcia abietis eonymphs (Insecta, Hymenoptera) enhancement of bioactivity by in vivo passaging. J Invertebr Pathol 1994, 64:62-64.

75. Steenberg $T$, Langer $V$, Esvjerg P: Entomopathogenic fungi in predatory beetles (Col.: Carabidae and Staphylinidae) from agricultural fields. Entomophaga 1995, 40:77-85.

76. Fargues J, Manlanla NK, Delmas JC: Infectivity of propagules of Paecilomyces fumosoroseus during in vitro development to Spodoptera frugiperda. J Invertebr Pathol 1994, 64:173-178.

77. Vidal C, Fargues J, Lacey LA, Jackson M: Effect of various liquid culture media on morphology, growth, propagule production, and pathogenic activity to Bemisia argentifolii of the entomopathogenic Hyphomycete, Paecilomyces fumosoroseus. Mycopathologia 1998, 143:33-46.

78. Kiwenick S, Sikora RA: Biological control of the root-knot nematode Meloidogyne incognita by Paecilomyces lilacinus strain 251. Biol Control 2006, 38:179-187.

79. Fiedler Z, Sosnowska D: Nematophagous fungus Paecilomyces lilacinus (Thom) Samson is also a biological agent for control of greenhouse insects and mite pests. Bio Control 2007, 52:547-558.

80. Gaspard JT, Jaffee BA, Ferris H: Association of Verticillium chlamydosporium and Paecilomyces lilacinus with root-knot nematode infested soil. $J$ Nematol 1990, 22:207-213.

81. Bourne JM, Kerry BR: Effect of the host plant on the efficacy of Verticillium chlamydosporium as a biological control agent of root-knot nematodes at different nematode densities and fungal application rates. Soil Biol Biochem 1999, 31:75-84.

82. Khambay BPS, Bourne JM, Cameron S, Kerry BR, Zaki M: A nematicidal metabolite from Verticillium chlamydosporium. Pest Manag Sci 2000, 56:1098-1099.

83. Sempere F, Santamarina MP: Suppression of Nigrospora oryzae (Berk. \& Broome) Petch by an aggressive mycoparasite and competitor, Penicillium oxalicum Currie \& Thom. Int J Food Microbiol 2008, 122:35-43.

84. Robert EC: MUSCLE: multiple sequence alignment with high accuracy and high throughput. Nucleic Acids Research 2004, 32:1792-1797.

doi:10.1186/1471-2148-10-68

Cite this article as: Li et al:: New insights into the evolution of subtilisinlike serine protease genes in Pezizomycotina. BMC Evolutionary Biology 2010 10:68.

\section{Submit your next manuscript to BioMed Central and take full advantage of:}

- Convenient online submission

- Thorough peer review

- No space constraints or color figure charges

- Immediate publication on acceptance

- Inclusion in PubMed, CAS, Scopus and Google Scholar

- Research which is freely available for redistribution

Submit your manuscript at www.biomedcentral.com/submit
Biomed Central 